\title{
Propofol induces rat embryonic neural stem cell apoptosis by activating both extrinsic and intrinsic pathways
}

\author{
WEI-WEI ZOU ${ }^{1}$, HUA-PING XIAO ${ }^{2}$, MIAO-NING GU ${ }^{3}$, KE-XUAN LIU $^{4}$ and ZHI-QUN LIU ${ }^{1}$ \\ ${ }^{1}$ Department of Anesthesiology, Zhongshan Hospital of Traditional Chinese Medicine, Zhongshan, Guangdong 528400; \\ ${ }^{2}$ Department of Anesthesiology, Jiangxi Cancer Hospital, Nanchang, Jiangxi 330000; ${ }^{3}$ Department of Anesthesiology, \\ Nanfang Hospital, Southern Medical University, Guangzhou, Guangdong 510000; ${ }^{4}$ Department of Anesthesiology, \\ The First Affiliated Hospital of Sun Yat-sen University, Guangzhou, Guangdong 510080, P.R. China
}

Received October 16, 2012; Accepted January 17, 2013

DOI: $10.3892 / \mathrm{mmr} .2013 .1298$

\begin{abstract}
Propofol has previously been shown to have detrimental effects on the developing brain. Neural stem cells, identified in the embryonic brain as well as in the adult brain, are multipotent, self-renewing cells, which are capable of differentiating into different phenotypes of the nervous system. The present study was designed to investigate propofol-induced rat embryonic neural stem cell apoptosis and its potential mechanisms. Rat embryonic neural stem cells were isolated, cultured and characterized. Treatment of these cultured stem cells with different doses of propofol was carried out and cell proliferation was assessed by MTT assay and apoptosis by flow cytometric analysis. Cellular levels of active forms of caspase-3 and caspase-8, which regulate the extrinsic apoptotic pathway, and of caspase- 9 and cytochrome $\mathrm{C}$, which regulate the intrinsic apoptotic pathway, were detected by western blotting. Over $95 \%$ of isolated rat embryonic neural stem cells expressed the Nestin protein, as detected by immunofluorescence staining. Using an in vitro cell culture system, we showed that propofol inhibited cell growth and induced cell apoptosis in a dosedependent manner. Furthermore, western blot analysis showed that propofol treatment significantly elevated levels of active forms of caspase-3, caspase- 8 , caspase- 9 and cytochrome $\mathrm{C}$ in the embryonic neural stem cells. Propofol induced rat embryonic neural stem cell apoptosis and activated caspase-3, caspase-8, caspase- 9 and cytochrome $C$, suggesting that propofol-induced stem cell apoptosis may be regulated through both the extrinsic and intrinsic apoptotic pathways.
\end{abstract}

Correspondence to: Dr Zhi-Qun Liu, Department of Anesthesiology, Zhongshan Hospital of Traditional Chinese Medicine, 3 Kangxin Road, Zhongshan, Guangdong 528400, P.R. China

E-mail: zouhuyang@gmail.com

Key words: propofol, neural stem cells, apoptosis

\section{Introduction}

Propofol is commonly used for the induction of anesthesia in surgical procedures worldwide. Its anesthetic action is believed to occur through potentiation of GABAA receptor activity. Propofol has also been widely used in pediatric anesthesia and in the pediatric critical care unit. It has been shown that repeated exposure of the developing brain to propofol results in neuronal cell apoptosis (1). Cattano et al reported that injection of propofol over a dose of $50 \mathrm{mg} / \mathrm{kg}$ into Day 5-7 C57BL6 rat neonates led to marked neuronal cell apoptosis (2). A similar result was observed by Fredriksson et al (3). It has been found that propofol or modulators of GABAA regulate intracellular $\mathrm{Ca}^{++}$concentration which contributes in part to cell apoptosis (4). However, the molecular mechanism by which propofol induces neuronal cell apoptosis remains largely to be elucidated.

Neural stem cells were first identified in the embryonic Day 13.5-14.5 rat forebrain in 1989 (5). Since then, they have been isolated from various areas of the adult brain (6,7). Neural stem cells are multipotent, self-renewing cells, capable of differentiating into different phenotypes of the nervous system. In this study, we isolated and cultured rat embryonic neural stem cells and investigated in vitro propofol-induced stem cell apoptosis. Furthermore, using western blot analysis, we examined the effect of propofol in activating several notable apoptotic proteins, i.e., cytochrome $\mathrm{C}$, caspase-3, caspase- 8 and caspase-9. It is known that caspase- 3 and -8 regulate the extrinsic apoptotic pathway while cytochrome $\mathrm{C}$ and caspase- 9 regulate the intrinsic apoptotic pathway (8-11). We believe that the identification of key players controlling the process of neuronal cell apoptosis induced by propofol may lead to the development of new methods to reduce the side-effects caused by propofol, particularly in pediatric patients.

\section{Materials and methods}

Ethics. Ethical approval for this study was provided by the Ethical Committee of Zhongshan Hospital of Traditional Chinese Medicine, Guangdong, China (Professor Zhong-Qing Wu) on 9 March, 2010. 
Isolation and culture of rat embryonic neural stem cells. Wistar rat embryos were obtained at 14-16 days of gestation by routine surgical procedure. The cerebral cortex was removed and immersed in D-Hanks solution. Blood vessels and meninges were removed followed by centrifugation at $1,000 \mathrm{rpm}$ for $3 \mathrm{~min}$, then the cerebral cortex was minced and treated with trypsin $(0.125 \%)$ and EDTA $(0.102 \%)$. Digestion with trypsin/EDTA was neutralized by addition of culture medium Dulbecco's modified Eagle's medium (DMEM)/F12 containing 10\% FBS, 2\% B27 and 1\% N2 supplements, $20 \mathrm{ng} / \mathrm{ml} \mathrm{EGF,} 20 \mathrm{ng} / \mathrm{ml} \mathrm{FGF,} 200 \mathrm{IU} / 1$ penicillin and $100 \mathrm{IU} / 1$ streptomycin. Cells were then dispersed by pipetting up and down several times and pelleted with centrifugation. After re-suspension with culture medium, cells were transferred into T 25 cell culture flasks $\left(0.5 \times 10^{6}\right.$ cells/ flask) previously coated with poly-ornithine and laminin and cultured at $37^{\circ} \mathrm{C}$ in a moist atmosphere containing $5 \% \mathrm{CO}_{2}$.

Immunofluorescence cell staining. Immunofluorescence cell staining was applied to characterize the rat embryonic neural stem cells using an anti-Nestin antibody. Cells (at passage 2-3) cultured in a 4-well chamber slide were washed once with phosphate-buffered saline (PBS) and fixed with $4 \%$ paraformaldehyde for $30 \mathrm{~min}$ at room temperature. After permeabilization with $0.5 \%$ Triton $\mathrm{X}-100$ and blocking with $5 \%$ goat serum, cells were washed three times with PBS. An anti-Nestin antibody was added to cells (an isotype was used as a control) and incubated overnight at $4^{\circ} \mathrm{C}$ followed by three washes with PBS. Cells were then incubated with a TRITCconjugated goat anti-rabbit IgG secondary antibody for $60 \mathrm{~min}$ in the dark followed by three washes with PBS. Cell nuclei were stained with DAPI for $3 \mathrm{~min}$. After three washes with PBS, cells were mounted with fluorescent mounting medium and studied under a fluorescent microscope.

MTT assay. MTT assay was employed to examine the effect of propofol on cell growth. Rat embryonic neural stem cells at passage 2 were seeded into a 96-well plate previously coated with poly-ornithine and laminin $\left(4 \times 10^{4}\right.$ cells/well) and cultured at $37^{\circ} \mathrm{C}$ for $24 \mathrm{~h}$ in a moist atmosphere containing $5 \% \mathrm{CO}_{2}$. Cells were washed once with PBS and propofol was added at different concentrations $(5,25,50$ and $100 \mu \mathrm{M})$ with some wells of cells treated with vehicle (intralipid) or left untreated. Each sample was duplicated. After culture for 12 h, $20 \mu 10.5 \%$ MTT was added into each well and cells were maintained in culture for another $4 \mathrm{~h}$. Cell medium was then aspirated and $100 \mu 110 \%$ DMSO was added to lyse cells for the release of MTT. The optical density of each well at a wavelength of $570 \mathrm{~nm}$ was measured and recorded with a standard ELISA microplate reader.

Flow cytometric analysis of cell apoptosis. Rat embryonic neural stem cells at passage 2 were seeded in $100-\mathrm{mm}$ cell culture dishes previously coated with $0.1 \%$ poly-L-lysine $\left(1.2 \times 10^{6}\right.$ cells/dish) and cultured at $37^{\circ} \mathrm{C}$ for $24 \mathrm{~h}$ in a moist atmosphere containing $5 \% \mathrm{CO}_{2}$. Cells were then treated with propofol $(5,25,50$ and $100 \mu \mathrm{M})$, intralipid or $50 \mu \mathrm{M}$ propofol $+2 \mu \mathrm{M}$ caspase-3 inhibitor Z-DEVD-FMK for $12 \mathrm{~h}$. After detachment with PBS/1 mM EDTA and washing twice with PBS, cells were re-suspended in $400 \mu \mathrm{l}$ binding buffer and mixed with $5 \mu \mathrm{l}$ FITC-conjugated Annexin V, then $5 \mu \mathrm{l}$ 7-amino-actinomycin was added to cells and incubated in the dark for $10 \mathrm{~min}$. Annexin V-FITC-positive cells (apoptotic cells) were analyzed by a flow cytometer.

Western blot analysis. Rat embryonic neural stem cells were treated with $50 \mu \mathrm{M}$ propofol for $12 \mathrm{~h}$. Total protein was extracted from cells using RIPA lysis buffer $(0.1 \%$ Nonidet $\mathrm{P}-40,0.5 \%$ sodium deoxycholate, $0.1 \%$ SDS, $1 \mathrm{mM}$ Tris- $\mathrm{HCl}$, $\mathrm{pH}$ 7.6, $50 \mathrm{mM} \mathrm{NaF}, 200 \mathrm{mM} \mathrm{NaCl}, 1 \mathrm{mM}$ EDTA, $1 \mathrm{mM}$ sodium orthovanadate and $1 \mathrm{mM}$ benzamidine) containing a proteinase inhibitor cocktail (1:100 dilution; Sigma, St. Louis, MO, USA). After quantification with a protein assay kit (Bio-Rad Laboratories, Hercules, CA, USA), $100 \mu \mathrm{g}$ protein in 1X Laemmli buffer was boiled for $5 \mathrm{~min}$, separated by SDS-PAGE and electrically transferred onto PVDF membrane. The membranes were blocked at room temperature in TBS-T buffer (50 mM Tris-HCl, $150 \mathrm{mM} \mathrm{NaCl,} \mathrm{pH} \mathrm{7.5,} \mathrm{0.1 \%}$ Tween-20) containing 5\% skimmed milk for $1 \mathrm{~h}$ followed by incubation with primary antibodies diluted in blocking buffer for $2 \mathrm{~h}$. All antibodies detected the active forms of proteins and were used as follows: anti-caspase-3 antibody (1:1,000), anticytochrome $\mathrm{C}$ antibody $(1: 2,000)$, anti-caspase- 9 antibody $(1: 1,000)$ and anti-caspase- 8 antibody $(1: 1,000)$. Following incubation with the primary antibody, the membranes were washed three times (15 min x 3) with TBS-T buffer followed by incubation with HRP-conjugated anti-mouse or anti-rabbit secondary antibodies (both at a dilution of 1:5,000; Promega, Madison, WI, USA) for $1 \mathrm{~h}$. The membranes were washed as above with TBS-T buffer and the specific bands were visualized using an ECL western blot detection reagent kit (Amersham Biosciences, Piscataway, NJ, USA), scanned and densitometrically analyzed with Molecular Analysis Program (Bio-Rad Laboratories, Shanghai, China). Relative quantification of each protein was performed following normalization against $\beta$-actin.

Statistical analysis. All data are expressed as the mean \pm standard error of the mean (SEM). Statistical analysis was performed using SPSS 13.0 software. One-way ANOVA and the least significant difference test were performed to compare differences among the groups. $\mathrm{P}<0.05$ was considered to indicate a statistically significant result.

\section{Results}

Isolation, culture and characterization of rat embryonic neural stem cells. Rat embryonic neural stem cells were isolated from E14-16 embryos and seeded in T25 flasks containing neural stem cell culture medium. Second day suspended stem cell colonies were observed. The cell colonies were dispersed and passaged, cells then grew and became adherent. For cell characterization, Nestin protein production was assayed by immunofluorescent staining using an anti-Nestin antibody. Positively stained cells were observed with fluorescence microscopy (Fig. 1B) and counted. The percentage of Nestin-positive cells was calculated from five different fields. The results from a total of four isolations are shown in the right panel of Fig. 1. The percentage of Nestinpositive cells ranged from 90.36 to $93.90 \%$ in each isolation. 

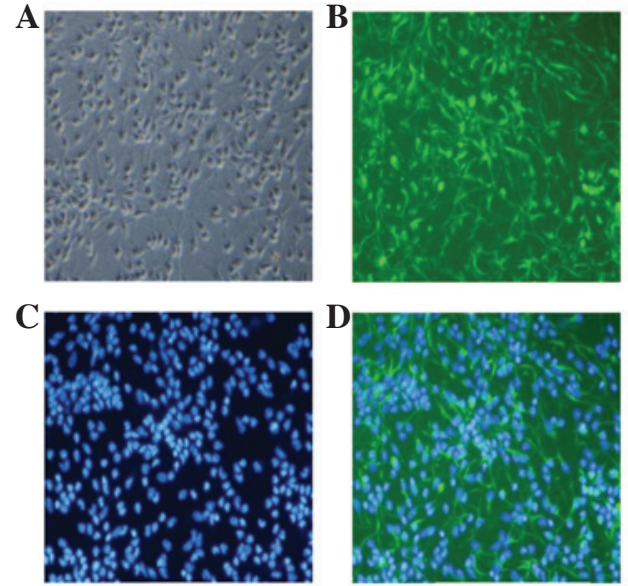

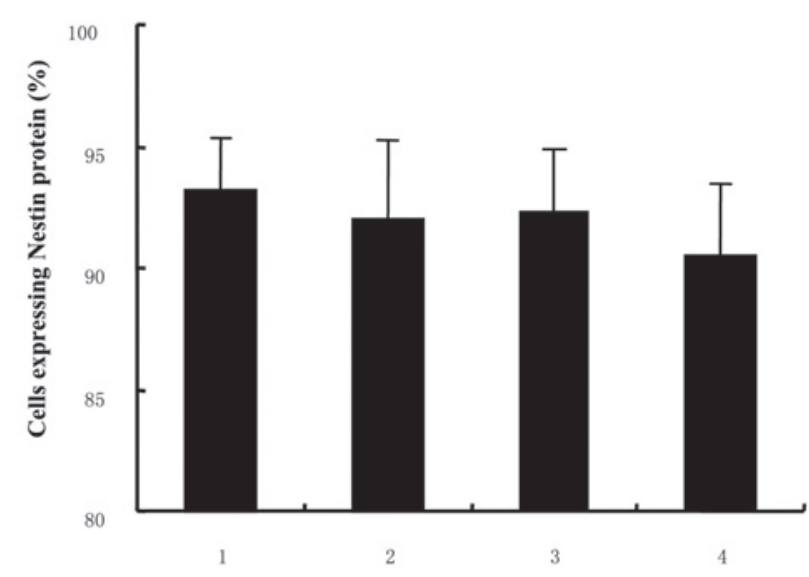

Figure 1. Characterization of isolated rat embryonic neural stem cells. The cells were isolated and cultured as described in Materials and methods. Cells at the second passage were stained with a fluorescence-labeled anti-Nestin antibody. Positively stained cells were observed with fluorescence microscopy (left panels A-D). (A) Bright field, (B) fluorescence-stained cells (Nestin-positive, green), (C) nuclear staining by DAPI (blue), (D) image showing (B) and (C) merged. The percentage of Nestin-positive cells over total cells in 5 different fields was calculated and averaged for each isolation. The results from a total of 4 isolations (numbers 1-4 along the $\mathrm{x}$-axis), are shown in the right panel. For every isolation examined, $>90 \%$ of cells were detected to express Nestin.

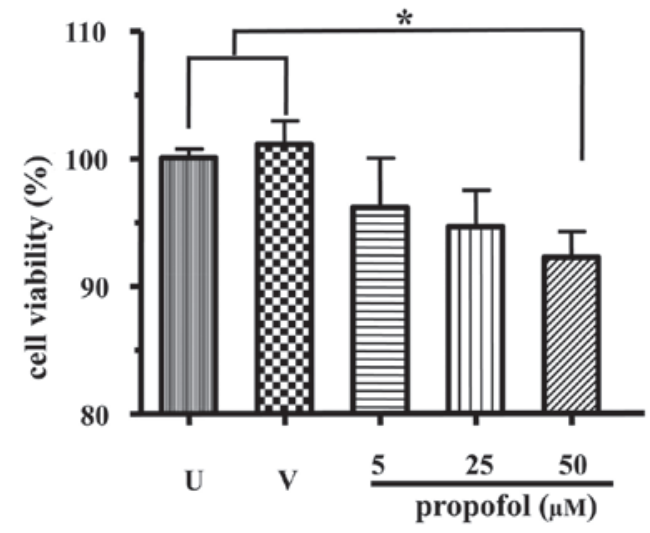

Figure 2. Propofol inhibited rat embryonic neural stem cell growth in a dosedependent manner. The MTT method was applied to measure cell growth. There was no difference observed in the MTT uptake in vehicle (intralipid)treated and untreated cells. By contrast, $50 \mu \mathrm{M}$ propofol significantly reduced the MTT uptake by rat embryonic neural stem cells ( $\mathrm{P}<0.01$, compared with untreated cells). The MTT uptake by non-treated cells was taken as $100 \%$. $\mathrm{U}$, untreated cells; V, vehicle-treated cells.

Inhibitory effect of propofol on rat embryonic neural stem cell growth. First, the effect of propofol on stem cell growth was examined. The MTT assay was employed for this purpose. As shown in Fig. 2, there was no significant difference in the uptake of MTT between the intralipid-treated and non-treated cells. However, propofol at $50 \mu \mathrm{M}$ significantly reduced the uptake of MTT by embryonic neural stem cells $(\mathrm{P}<0.05$, compared with untreated or intralipid-treated cells), indicating that propofol inhibited stem cell growth.

Propofol induces apoptosis of rat embryonic neural stem cells. Next, we studied whether propofol induced rat embryonic neural stem cell apoptosis. Cells were treated with different doses of propofol as indicated. At different time points (6, 12 and $24 \mathrm{~h}$ ) post-treatment, cell apoptosis was assayed with flow cytometric analysis. We found that significant apoptosis occurred after cells were treated for $12 \mathrm{~h}$ (data not shown).
We therefore used this time point for the apoptosis assay. As shown in Fig. 3, no significant difference was observed in cell apoptosis between intralipid-treated and untreated cells (both at $\sim 3 \%$ ). By contrast, propofol treatment starting at $5 \mu \mathrm{M}$ induced cell apoptosis, doubling that of untreated cells. With the increase of propofol concentration, the cell apoptosis increased accordingly in a dose-dependant manner. When treated with $50 \mu \mathrm{M}$ propofol, cell apoptosis reached $\sim 30 \%$, significantly higher than the untreated cells $(\mathrm{P}<0.001)$. The addition of caspase-3 inhibitor Z-DEVD-FMK resulted in a significant reduction in cell apoptosis (from $~ 30$ to $19 \%$, $\mathrm{P}<0.001)$ in the $50 \mu \mathrm{M}$ group.

Propofol activates apoptotic proteins in rat embryonic neural stem cells. To investigate the mechanisms controlling stem cell apoptosis induced by propofol, we detected cellular levels of active caspases-3, -8, -9 and cytochrome $\mathrm{C}$ in rat embryonic neural stem cells following treatment with propofol. Western blot analysis showed that there was no difference in the levels of all active proteins between untreated and vehicle (intralipid)treated cells. However, propofol treatment resulted in a significant augmentation of all active proteins assayed (Fig. 4), i.e., active caspase-3 from $99.9 \pm 5.2$ to $216.2 \pm 12.1(\mathrm{P}<0.001)$, active caspase- 8 from $100.0 \pm 6.5$ to $183.6 \pm 17.8(\mathrm{P}<0.01)$, active caspase-9 from $99.9 \pm 1.6$ to $341.2 \pm 18.5(\mathrm{P}<0.0001)$ and cytochrome $\mathrm{C}$ from $99.9 \pm 2.5$ to $218.5 \pm 6.6(\mathrm{P}<0.001)$.

\section{Discussion}

Anesthetic drugs are used frequently in pediatric medicine for surgery as well as for other procedures such as angiography, central line catheterization, endoscopy and intubation. It is known that many of these agents cause damage to the developing brain. Several studies demonstrated that administration of isoflurane, ketamine, nitric oxide, midazolam, thiopental and sevoflurane results in neuronal apoptosis in the developing mouse brain $(3,12,13)$. In the present study, we investigated the effect of propofol on rat embryonic neural stem cells and found that i) $>90 \%$ rat neuronal stem cells isolated from E14-16 rat 
untreated

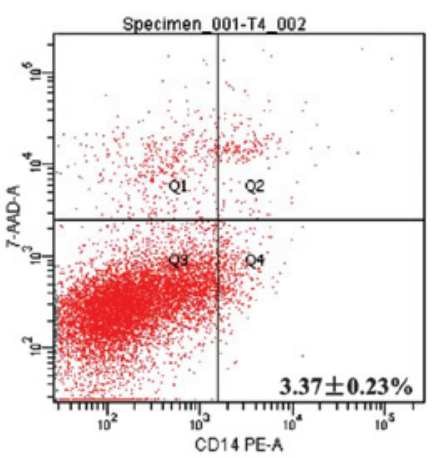

$25 \mu \mathrm{M}$

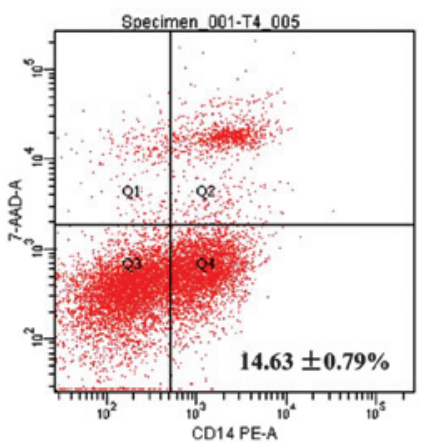

intralipid

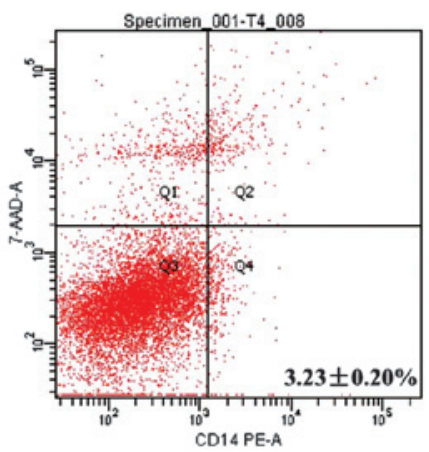

$50 \mu \mathrm{M}$

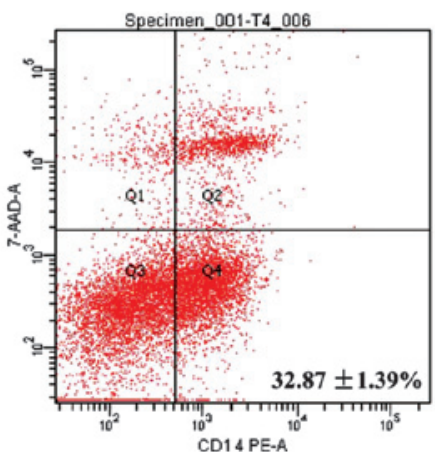

$5 \mu \mathrm{M}$

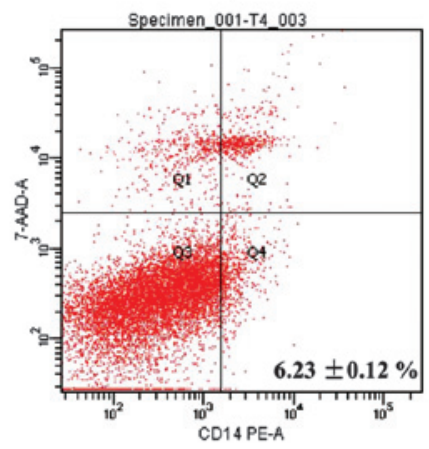

$50 \mu \mathrm{M}+$ inhibitor

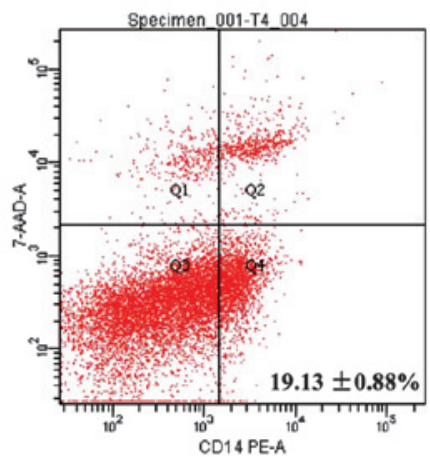

Figure 3. Propofol-induced rat embryonic neural stem cell apoptosis detected by flow cytometric analysis. There was no difference in cell apoptosis between vehicle (intralipid)-treated cells and untreated cells (both at $3 \%$ ). By contrast, propofol induced cell apoptosis in a dose-dependent manner. Treatment of cells with $5 \mu \mathrm{M}$ propofol resulted in $\sim 6.0 \%$ cell apoptosis, with the increase of propofol concentration to $50 \mu \mathrm{M}$. Approximately $30 \%$ of cells underwent apoptosis $(\mathrm{P}<0.05$, compared with untreated cells; $\mathrm{n}=4$ ). The caspase-3 inhibitor Z-DEVD-FMK significantly reduced cell apoptosis induced by $50 \mu \mathrm{M}$ propofol (from $32.87 \pm 1.39$ to $19.13 \pm 0.88, \mathrm{n}=4, \mathrm{P}<0.05)$.

A

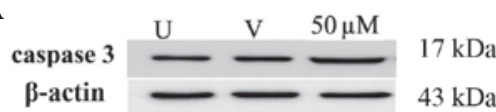

B

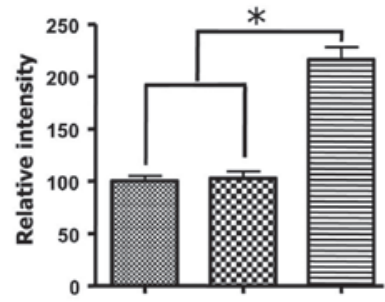

C

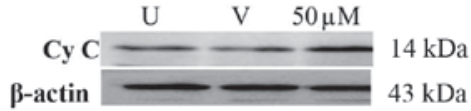

D

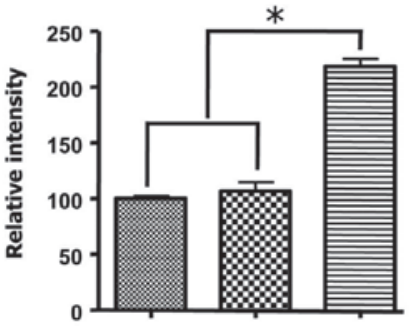

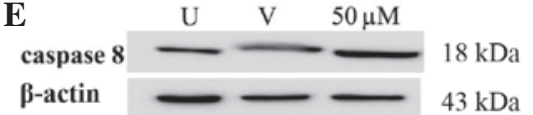

$\mathbf{F}$
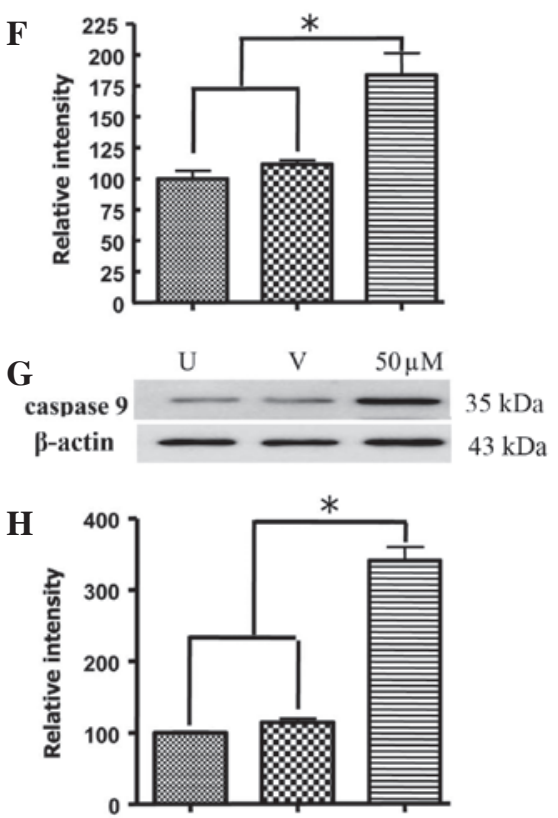

Figure 4. Propofol activated apoptotic proteins involved in the extrinsic and intrinsic apoptotic pathways. Rat embryonic neural stem cells were treated with $50 \mu \mathrm{M}$ propofol and active forms of caspase- $-3,-8$ and -9 and cytochrome $\mathrm{C}$ were assayed by western blotting. While intralipid treatment of cells did not result in a change in the levels of the proteins (active forms), propofol significantly augmented the levels of all four proteins as compared with untreated cells ( $\mathrm{P}<0.01$, $\mathrm{n}=4$ ). (A) A representative blot for active caspase 3 whose levels were semi-quantified and summarized in (B). (C) A representative blot for active cytochrome C whose levels were semi-quantified and summarized in (D). (E) A representative blot for active caspase 8 whose levels were semi-quantified and summarized in $(F) .(G)$ A representative blot for active caspase 9 whose levels were semi-quantified and summarized in $(\mathrm{H})$. $U$, untreated cells; $\mathrm{V}$, vehicle-treated cells. 
embryos expressed Nestin protein, ii) propofol inhibited stem cell growth and induced cell apoptosis in a dose-dependent manner, and iii) propofol activated caspase-3, -8 and -9 and cytochrome $\mathrm{C}$, which are key players in regulating extrinsic or intrinsic cell apoptosis pathways.

Studies measuring the brain uptake of propofol in humans following intravenous administration revealed that the concentration of propofol in the brain varied from patient to patient, ranging from 22 to $73 \mu \mathrm{M}$ (14). In the present study we used 5-100 $\mu \mathrm{M}$ propofol, relative to clinical application, to study its effect on neural stem cells. Rat embryonic neural stem cells were isolated from E14-16 embryos when the rat embryonic neural stem cells are most robust in differentiation and proliferation. The expression of Nestin protein, a widely used marker for the characterization of neural stem cells, was detected in the isolated cells (15). Using different assays, propofol was found to inhibit stem cell growth and induce cell apoptosis in a dose-dependent manner, which is in agreement with the results from in vivo studies showing that propofol induced neuronal cell apoptosis in the developing brain $(2,3)$.

There are two apoptotic pathways, i.e., the intrinsic and extrinsic pathways, both requiring caspase activation (9). The extrinsic pathway is triggered by extracellular ligands such as FasL and TNF- $\alpha$ super family members, that bind the extracellular domains of transmembrane receptors, through which the signal is transmitted to the cytosol, leading to the activation of caspase- 8 and caspase-3 (11). Cell apoptosis through the intrinsic pathway requires activation of caspase-9. Downregulation of anti-apoptotic Bcl-2 family members such as Bcl-xL, increase of mitochondria permeability and the release of cytochrome $\mathrm{C}$ from the mitochondria are associated with the intrinsic pathway (11). In the present study, we found that propofol treatment of rat embryonic neuronal stem cells resulted in the elevation of active proteins regulating the intrinsic apoptotic pathway (cytochrome $\mathrm{C}$ and caspase-9) as well as the extrinsic pathway (caspase- 8 and -3 ), suggesting that propofol may induce neuronal stem cell apoptosis through both pathways. However, these two pathways are not independent of each other. For example, caspase- 8 activated by the extrinsic pathway cleaves Bid to produce $\mathrm{tBid}$. $\mathrm{tBid}$ transferred into mitochondria stimulates the release of cytochrome $\mathrm{C}$ which together with the cytosolic protein Apaf-1 activates caspase-9, amplifying the apoptotic effect of the extrinsic pathway. The addition of caspase-3 inhibitor Z-DEVD-FMK partially abolished the apoptotic effect of propofol, indicating that the induction cell apoptosis by propofol is caspase-dependent.

Mechanisms of cell survival also modulate cell apoptosis. It has been revealed that general anesthesia inhibits the production of neuronal growth factors, such as brain-derived neurotrophic factor (BDNF), nerve growth factor (NGF) and neurotrophin-3 (NT-3) (16). Neuronal growth factors activate Trk and p75 NTR receptors, leading to the phosphorylation of Akt, an important kinase controlling cell survival and growth $(17,18)$. Lu et al reported that the exposure of neonatal mice to midazolam, isoflurane and nitrous oxide resulted in neuroapoptosis, which is attributed, at least in part, to the reduced level of BDNF (19). Synaptic proteins are essential for the formation of synapses. Nikizad et al showed that levels of several synaptic proteins such as synaptophysin, synaptobrevin and amphiphysin in the cerebral cortex and the thalamus regions were decreased following exposure to general anesthesia (midazolam, nitrous oxide and isoflurane) in 7-day-old rat pups (20). Recently, Pesić et al studied the mechanism of propofol inducing neuronal cell death and found that propofol inhibited NGF production, which contributed to cell death (21). In this study, the effects of propofol on the expression of neuronal growth factors in rat embryonic neural stem cells were not explored, and therefore remain to be investigated.

Increasing evidence has shown that anesthetic drugs cause neuronal cell apoptosis in the brain, and that the developing brain is particularly sensitive to the drug. The timing and duration of exposure determine the severity of cell damage (22-25). Neural stem cells play a significant role during development, producing the enormous diversity of cells in the brain, including neurons. The present study, to the best of our knowledge, is the first to explore the effect of propofol on neural stem cells. Our results show that propofol induces significant neural stem cell apoptosis, adding new evidence of the detrimental effect of anesthetic drugs on the developing brain, suggesting that clinical application of propofol should be carefully considered in pediatric patients, and if inevitable, large dosage and repeated use of propofol should be avoided.

\section{Acknowledgements}

The authors thank Dr Shu-Ji Li (Laboratory of Medical Neurobiology, School of Basic Medical Science, Southern Medical University, China) for his experienced advice. The Bureau of Science and Technology Development (Zhongshan City, Guangdong, China; grant number 20102A113) fully financed the study.

\section{References}

1. Bercker S, Bert B, Bittigau P, et al: Neurodegeneration in newborn rats following propofol and sevoflurane anesthesia. Neurotox Res 16: 140-147, 2009.

2. Cattano D, Young C, Straiko MM and Olney JW: Subanesthetic doses of propofol induce neuroapoptosis in the infant mouse brain. Anesth Analg 106: 1712-1714, 2008.

3. Fredriksson A, Pontén E, Gordh T and Eriksson P: Neonatal exposure to a combination of N-methyl-D-aspartate and gammaaminobutyric acid type A receptor anesthetic agents potentiates apoptotic neurodegeneration and persistent behavioral deficits. Anesthesiology 107: 427-436, 2007.

4. Kahraman S, Zup SL, McCarthy MM and Fiskum G: GABAergic mechanism of propofol toxicity in immature neurons. J Neurosurg Anesthesiol 20: 233-240, 2008.

5. Temple S: Division and differentiation of isolated CNS blast cells in microculture. Nature 340: 471-473, 1989.

6. Reynolds BA and Weiss S: Generation of neurons and astrocytes from isolated cells of the adult mammalian central nervous system. Science 55: 1707-1710, 1992.

7. Taupin P and Gage FH: Adult neurogenesis and neural stem cells of the central nervous system in mammals. J Neurosci Res 69: 745-749, 2002.

8. Kroemer G, Galluzzi L and Brenner C: Mitochondrial membrane permeabilization in cell death. Physiol Rev 87: 99-163, 2007.

9. Meier P and Vousden KH: Lucifer's labyrinth - ten years of path finding in cell death. Mol Cell 28: 746-754, 2007.

10. Youle RJ and Strasser A: The BCL-2 protein family: opposing activities that mediate cell death. Nat Rev Mol Cell Biol 9: 47-59, 2008.

11. Riedl SJ and Salvesen GS: The apoptosome: signalling platform of cell death. Nat Rev Mol Cell Biol 8: 405-413, 2007. 
12. Zhang X, Xue Z and Sun A: Subclinical concentration of sevoflurane potentiates neuronal apoptosis in the developing C57BL/6 mouse brain. Neurosci Lett 447: 109-114, 2008.

13. Young C, Jevtovic-Todorovic V, Qin YQ, et al: Potential of ketamine and midazolam, individually or in combination, to induce apoptotic neurodegeneration in the infant mouse brain. Br J Pharmacol 146: 189-197, 2005.

14. Ludbrook GL, Visco E and Lam AM: Propofol: relation between brain concentrations, electroencephalogram, middle cerebra artery blood flow velocity, and cerebral oxygen extraction during induction of anesthesia. Anesthesiology 97: 1363-1370, 2002.

15. Johansson CB, Momma S, Clarke DL, et al: Identification of a neural stem cell in the adult mammalian central nervous system. Cell 96: 25-34, 1999.

16. Bibel M and Barde YA: Neurotrophins: key regulators of cell fate and cell shape in the vertebrate nervous system. Genes Dev 14: 2919-2937, 2000.

17. Dudek H, Datta SR, Franke TF, et al: Regulation of neuronal survival by the serine-threonine protein kinase Akt. Science 275: 661-665, 1997.

18. Bittigau P, Sifringer M, Genz K, et al: Antiepileptic drugs and apoptotic neurodegeneration in the developing brain. Proc Natl Acad Sci USA 99: 15089-15094, 2002.
19. Lu LX, Yon JH, Carter LB and Jevtovic-Todorovic V: General anesthesia activates BDNF-dependent neuroapoptosis in the developing rat brain. Apoptosis 11: 1603-1615, 2006.

20. Nikizad H, Yon JH, Carter LB and Jevtovic-Todorovic V: Early exposure to general anesthesia causes significant neuronal deletion in the developing rat brain. Ann NY Acad Sci 1122: 69-82, 2007.

21. Pesić V, Milanović D, Tanić N, et al: Potential mechanism of cell death in the developing rat brain induced by propofol anesthesia. Int J Dev Neurosci 27: 279-287, 2009.

22. Rizzi S, Ori C and Jevtovic-Todorovic V: Timing versus duration: determinants of anesthesia-induced developmental apoptosis in the young mammalian brain. Ann NY Acad Sci 1199: 43-51, 2010

23. Rizzi S, Carter LB, Ori C and Jevtovic-Todorovic V: Clinical anesthesia causes permanent damage to the fetal guinea pig brain. Brain Pathol 18: 198-210, 2008.

24. Slikker W Jr, Zou X, Hotchkiss CE, et al: Ketamine-induced neuronal cell death in the perinatal rhesus monkey. Toxicol Sci 98: 145-158, 2007.

25. Yon JH, Daniel-Johnson J, Carter LB and Jevtovic-Todorovic V: Anesthesia induces neuronal cell death in the developing rat brain via the intrinsic and extrinsic apoptotic pathways. Neuroscience 135: 815-827, 2005. 